\section{Struktur Komunitas Plankton pada Air Kolam Ikan Lele yang Berbeda Warna}

\section{Plankton Community Structure in Different Water Coloration of Catfish Ponds}

\author{
Karunia Adetera Nungki Wijayanti ${ }^{1}$, Murwantoko Murwantoko*2 \& Indah Istiqomah ${ }^{2}$ \\ ${ }^{1}$ Program Magister IImu Perikanan, Departemen Perikanan, Fakultas Pertanian, Universitas Gadjah Mada, Yogyakarta, Indonesia \\ ${ }^{2}$ Departemen Perikanan, Fakultas Pertanian, Universitas Gadjah Mada, Yogyakarta, Indonesia \\ *Penulis korespondensi, email: murwantoko@ugm.ac.id
}

Tanggal Submisi: 31 Desember 2020; Tanggal Revisi: 29 Maret 2021; Tanggal Penerimaan: 21 April 2021

\begin{abstract}
ABSTRAK Plankton dalam perairan memiliki peranan yang penting sebagai produsen serta penyuplai nutrisi maupun indikator lingkungan. Struktur komunitas dan faktor pendukung lingkungan berpengaruh terhadap keadaan ekosistem perairan budidaya serta pengaruhnya pada komoditas budidaya. Penelitian ini membahas mengenai struktur komunitas plankton pada air kolam lele yang berbeda warna. Kolam yang digunakan adalah kolam budidaya lele air hijau di Kalasan, cokelat di Prambanan, dan merah di Berbah, Sleman. Parameter kualitas air yang meliputi pH, suhu, bahan organik, dan oksigen terlarut diukur sebanyak 3 kali setiap 2 minggu sekali dan kadar nitrat, nitrit, amonia diukur pada saat awal sampling. Pengambilan sampel plankton dilakukan dengan menggunakan plankton net sebanyak 3 kali setiap 2 minggu sekali. Jenis dan jumlah plankton diamati secara mikroskopis. Penentuan jenis plankton dilakukan dengan membandingkan ciri-ciri yang tampak dengan literatur. Dominansi plankton, diversitas plankton, kepadatan serta pengaruh kualitas air terhadap struktur komunitas plankton dianalisis secara statistik. Hasil pegamatan menunjukan plankton yang mendominansi adalah Chlorophyta dengan nilai indeks diversitas maupun dominansi di semua jenis kolam tergolong rendah-sedang. Berdasarkan uji statistik menunjukkan kualitas air yang berpengaruh terhadap struktur komunitas plankton adalah bahan organik, amonia, dan nitrit. Struktur komunitas plankton pada air kolam berbeda warna menunjukkan terdapat 15 filum yang terdiri dari 32 kelas. Plankton yang dominan pada kolam warna air hijau adalah Microcystis aeruginosa, sedangkan kolam cokelat dan merah adalah Chlorella varigatus. Nilai diversitas dan dominansi pada ketiga warna air cenderung stabil moderat, karena termasuk dalam kategori sedang yang menunjukan kondisi kolam tergolong stabil dan baik untuk budidaya.
\end{abstract}

Kata kunci: Struktur komunitas, plankton, lele, kualitas air

ABSTRACT Plankton in waters has an important role as a producer as well as a supplier of nutrients and environmental indicators. The structure of the plankton community and environmental supporting factors influence the state of the aquaculture ecosystem and affect the cultivated commodities. This research discusses the structure of the plankton community in catfish pond water of different colors. The ponds were green water catfish cultivation ponds in Kalasan, brown water ponds in Prambanan, and red water ponds in Berbah, Sleman. Water quality parameters including $\mathrm{pH}$, temperature, organic matter, and dissolved oxygen were measured 3 times every 2 weeks and the levels of nitrate, nitrite, ammonia were measured at the start of the sampling. Plankton sampling was carried out using a plankton net 3 times every 2 weeks. The types and amounts of plankton were observed microscopically. Determination of plankton type is done by comparing the features that appear with the literature. Dominance, diversity, the density of plankton, and the influence of water quality on the structure of the plankton community were analyzed statistically. The results showed that the dominant plankton was Chlorophyta with low to medium diversity and dominance index values in all types of ponds. Based on statistical tests, it shows that the water quality that affects the plankton community structure is organic matter, ammonia, and nitrite. The structure of the plankton community in different ponds shows 15 phyla consisting of 32 classes. The dominant plankton in green water ponds is Microcystis aeruginosa, while the brown and red water ponds are Chlorella varigatus. The diversity and dominance values of the three different color of pond water tend to be moderately stable, because they are included in the moderate category which showed that the ponds are classified as stable and good for culture.

Keywords: community structure, plankton, catfish, water quality

\section{PENDAHULUAN}

Plankton merupakan kelompok organisme baik hewan maupun tumbuhan yang terapung di dalam air, memiliki sedikit mobilitas atau mobilitas dan tidak mampu untuk melawan arus air. Plankton dibagi 5 menjadi 2 kelompok yaitu fitoplankton dan zooplankton (Junaidi et al., 2018).
Fitoplankton merupakan organisme yang bersifat autotrof dan merupakan penyumbang makanan alami dalam perairan, sedangkan zooplankton merupakan organisme bersifat heterotrofik (Sari et al., 2018). Plankton dalam perairan sangat penting karena memiliki peran penting dalam produksi serta penyuplai nutrisi, dapat digunakan sebagai sumber pakan alami, serta dapat menjadi indikator 
biologis penting untuk memantau dan mengevaluasi tingkat pencemaran lingkungan air (Nontji, 2008; Thirunavukkarasu etal., 2013; Gao etal., 2018).

Struktur komunitas merupakan spesies-spesies yang berada di dalam komunitas, terikat dalam interaksi biotik dan berfungsi sebagai unit terpadu meliputi komposisi jenis, densitas (Kerapatan), indeks dominansi, indeks keanekaragaman, dan indeks kelimpahan (Heddy, 1994). Komposisi jenis, keanekaragaman, dominansi, dan kelimpahan plankton dapat menunjukkan tingkat kompleksitas dari struktur komunitas biota perairan. Struktur komunitas plankton tersebut menandakan kestabilan serta kesuburan suatu perairan (Odum, 1993; Sari et al., 2018). Keanekaragaman jenis plankton merupakan penggambaran secara matematika yang dapat menggambarkan struktur kehidupan dan mempermudah analisis informasi-informasi tentang jenis dan jumlah plankton (Rahmatullah et al., 2016).

Komposisi dan kelimpahan fitoplankton akan berubah pada berbagai tingkatan sebagai respon terhadap perubahan kondisi lingkungan baik fisik, kimia, maupun biologi (Moersidik \& Hardjojo, 1998). Keanekaragaman dan kelimpahan plankton di perairan dipengaruhi oleh beberapa parameter dan karakteristik lingkungan. Karakteristik lingkungan tersebut yang secara fisiologis berpengaruh antara lain faktor fisikokimia perairan seperti intensitas cahaya, kecerahan, salinitas, oksigen terlarut, stratifikasi suhu, dan ketersediaan unsur hara nitrit dan fosfor, serta aspek biologis seperti aktivitas predasi oleh hewan, kematian alami, dan dekomposisi. Semakin tinggi kandungan nutrien di suatu perairan, maka kelimpahan fitoplankton di perairan tersebut akan semakin tinggi (Boyd, 1982; Barus, 2004; Gusmewati \& Deswati, 2018; Hesti et al., 2018).

Berdasarkan survei lapangan, terdapat perbedaan warna air kolam lele di lapangan. Warna air kolam lele tersebut meliputi warna air merah, hijau, dan coklat, namun tidak diketahui pengaruh warna air tersebut terhadap struktur komunitas plankton pada air. Struktur komunitas dan faktor pendukung lingkungan memberikan pengaruh yang sangat besar dalam keadaan ekosistem perairan budidaya serta pengaruhnya terhadap komoditas budidaya. Hal ini menjadikan diperlukannya penelitian yang membahas struktur komunitas plankton pada air kolam yang berbeda warna.

\section{BAHAN DAN METODE}

Alat dan bahan

Bahan yang digunakan pada penelitian ini antara lain sampel air dari kolam lele untuk mengetahui komposisi bakteri serta kualitas air kolam; larutan formalin untuk koleksi plankton, larutan kalium permanganat $\left(\mathrm{KMnO}_{4}\right)$ $0,01 \mathrm{~N}$, larutan asam sulfat $\left(\mathrm{H}_{2} \mathrm{SO}_{4}\right) 8 \mathrm{~N}$, larutan asam oksalat $\left(\mathrm{H}_{2} \mathrm{C}_{2} \mathrm{O}_{4}\right) 0,01 \mathrm{~N}$, dan larutan natrium hidroksida $(\mathrm{NaOH}) 0,1 \mathrm{M}$ untuk analisia kandungan bahan organik. Alat yang digunakan antara lain botol oksigen, pipet ukur, erlenmeyer, gelas ukur, bubble drop, plankton net, Sedgewigck Rafter, Water Quality Checker (WQC) (YSi 556), dan mikroskop cahaya (Olympus CX21).

Lokasi pengambilan sampel dilakukan di 9 kolam budidaya ikan lele yang ada di Kecamatan Kalasan (kolam air warna hijau (H1, H2, H3)), Prambanan (kolam air berwarna cokelat (C1, C2, C3)), dan Banguntapan (kolam air berwarna merah (M1, M2, M3)). Waktu pengambilan sampel dilakukan sebanyak tiga kali dalam waktu sebulanpada masing-masing kolam dengan rentang waktu dua minggu.

\section{Metode pengambilan sampel}

Parameter yang diamati meliputi kondisi biologi, fisik dan kimia perairan. Parameter biologi terdiri atas keanekaragaman dan dominansi plankton. Parameter fisik perairan yang diamati adalah suhu, sedangkan parameter kimia perairan yang diamati adalah kadar oksigen terlarut (Dissolved Oxygen), pH, kadar amoniak, nitrit, nitrat, dan bahan organik (BO).

Pengambilan sampel plankton dilakukan dengan cara mengambil air kolam sebanyak 20 liter kemudian disaring dengan menggunakan plankton net (jaring plankton). Hasil saringan ditampung pada botol plastik berukuran $50 \mathrm{ml}$ dan dikoleksi menggunakan larutan formalin $4 \%$. Pengukuran parameter perairan di lapangan dilakukan menggunakan alat Water Quality Checker (WQC). Parameter yang diamati adalah suhu, pH, dan kadar oksigen terlarut sebanyak tiga kali dengan rentang waktu dua minggu. Pengambilan sampel amonia, nitrat, nitrit dan bahan organik dilakukan dengan mengambil sampel air saat sampling pertama (amonia, nitrat, dan nitrit) dan tiap dua minggu sekali sebanyak tiga kali untuk bahan organik. Sampel air untuk amoniak dan bahan organik tersebut disimpan dalam cool box. Selanjutnya air akan dianalisis di Laboratorium Hidrologi dan Klimatologi Lingkungan dan Laboratorium Ekologi Perikanan Universitas Gadjah Mada untuk mengetahui kadar amonia, nitrat, dan nitrit menggunakan metode spektrofotometri dan bahan organik menggunakan metode permanganatmeter dalam sampel air tersebut.

\section{Pengamatan plankton}

Sampel hasil saringan dianalisis menggunakan SR (Sedgewick Rafter) di bawah mikroskop cahaya dengan perbesaran 100x dan 400x. Identifikasi plankton mengacu pada buku identifikasi Shirota (1996) dan Mc.Garaghan (2018).

\section{Analisis data}

Keragaman komunitas dalam keseluruhan komunitas dihitung dengan rumus indeks keragaman ShannonWiener (H') (Sunarto, etal. 2014):

$$
\mathrm{H}^{\prime}=-\sum \text { piln } p i
$$

Keterangan:

H' : Indeks keanekaragaman; pi : proporsi dari tiap species $i ; p i=\frac{n i}{N}$ ni : jumlah individu i;

$\mathrm{N}$ : jumlah total individu.

Indeks dominansi Simpson dihitung dengan rumus:

$$
C=\sum\left(\frac{n i}{N}\right)
$$

Keterangan:

C : Indeks dominansi

ni : jumlah individu dari jenius ke-i

$\mathrm{N}$ : jumlah total individu. 
Densitas (kelimpahan) plankton digunakan untuk mengetahui dinamika plankton pada kolam budidaya. Rumus yang digunakan adalah:

$$
\mathrm{N}=\frac{n s}{v c} \times \frac{v \mathrm{a}}{v c}
$$

Keterangan:

$\mathrm{N}$ : Jumlah sel per liter

ns: Jumlah sel per SR

va: Volume botol sampel

vs: Volume SR

vc: Volume disaring

Data yang diperoleh ditampilkan dengan menggunakan software Microsoft Excel 2013 dalam bentuk grafik, dan analisis statistik menggunakan software SPSS (versi 18).

Uji statistik dilakukan dengan melakukan uji Normalitas serta uji Homogenitas terlebih dahulu untuk menentukan uji statistik parametrik atau non-parametrik yang digunakan. Uji ANOVA digunakan pada parameter $\mathrm{pH}$, amonium, dan nitrat untuk melihat beda nyata antar perlakuan dalam masing-masing parameter, karena data masing-masing parameter berdistribusi normal serta homogen dengan uji lanjut menggunakan uji LSD (Least Significant Difference), adapun untuk data yang tidak berdistribusi normal dan ataupun tidak homogen (DO,suhu, bahan organik dan nitrit) menggunakan uji Kruskal-Walis dengan uji lanjut T-test (DO) ataupun uji Mann-Whitney (bahan organik dan nitrit). Tingkat kepercayaan sebesar 95\% $(\alpha=0,05)$ digunakan untuk semua uji statistik. Analisis statistik menggunakan softwere SPSS versi 18.

\section{HASIL DAN PEMBAHASAN}

\section{Kepadatan plankton}

Tabel 1. Kepadatan (N) plankton (idv/I) pada kolam air hijau, cokelat, dan merah.

\begin{tabular}{cccc}
\hline \multirow{2}{*}{ Kolam } & \multicolumn{3}{c}{$\mathrm{N}$} \\
\cline { 2 - 4 } & SamplingI & Sampling II & Sampling III \\
\hline H1 & $1,520,250$ & $2,846,250$ & $1,708,500$ \\
H2 & $1,404,000$ & $1,076,250$ & 886,500 \\
H3 & 743,250 & $1,353,750$ & 465,750 \\
C1 & 486,833 & $9,007,500$ & $3,517,500$ \\
C2 & $5,520,000$ & $3,367,500$ & $8,737,500$ \\
C3 & $1,860,000$ & $3,945,000$ & $8,272,500$ \\
M1 & $1,147,500$ & $2,452,500$ & 29,250 \\
M2 & $4,035,000$ & 376,500 & 55,500 \\
M3 & $4,575,000$ & 349,500 & 36,750 \\
\hline
\end{tabular}

Hasil pengamatan menunjukan bahwa kolam dengan air berwarna hijau terdapat 70 spesies plankton yang ditemukan. Kolam air warna cokelat terdapat 79 spesies, sedangkan pada kolam air warna merah terdapat 58 spesies. Berdasarkan analisis komunitas plankton didapatkan bahwa ketiga warna air kolam mengandung jenis plankton dominan yang berbeda. Plankton pada air kolam hijau didominansi oleh plankton Microcystis aeruginosa, Chlorella varigatus, Sphaerocystis schroeteri, Radiococcus planktonicus, dan Pediastrum boryanum var. Longicorne. Plankton pada air kolam cokelat didominansi oleh plankton C. varigatus, Cyclotella sp., Scenedesmus sp., Echinosphaerella limnetica, dan Lyngbya sp.. Plankton pada air kolam merah didominansi oleh plankton $C$. varigatus, Synedra sp., Elosa woralli, Amoeba sp., dan Haematococcus pluvialis.

Berdasarkan analisis kepadatan plankton didapatkan kepadatan plankton dengan nilai $\mathrm{N}$ berkisar antara 29,250-9,007,500 idv/l (Tabel 1). Keanekaragaman plankton tertinggi terdapat pada kolam Cokelat 1 pada sampling ke II, sedangkan nilai terendah adalah pada kolam Merah 1 pada sampling ke III. Nilai rata-rata keanekaragaman plankton antar warna antara lain kolam hijau dengan nilai rata-rata 1,333,833 dan 4,968,259 pada kolam cokelat, sedangkan pada kolam merah adalah 1,450,833. Adanya lonjakan kenaikan kepadatan pada kolam coklat sampling I ke sampling || dikarenakan pada sampling ke II plankton memasuki fase log dimana pertumbuhan terjadi peningkatan cepat. Fase log diawali oleh pembelahan jumlah sel dengan laju pertumbuhan cepat. Laju pertumbuhan pada fase ini mencapai maksimal pada kondisi kultur yang optimum (Harianto \& Azim, 2012). Berdasarkan uji Kruskal-Walis dari ketiga warna kolam dengan kepadatan plankton $(\mathrm{N})$ menunjukkan bahwa terdapat perbedaan signifikan antar warna kolam. Berdasarkan uji lanjut Mann-Whitney menunjukkan bahwa beda nyata terdapat pada kolam air cokelat terhadap hijau dan merah.

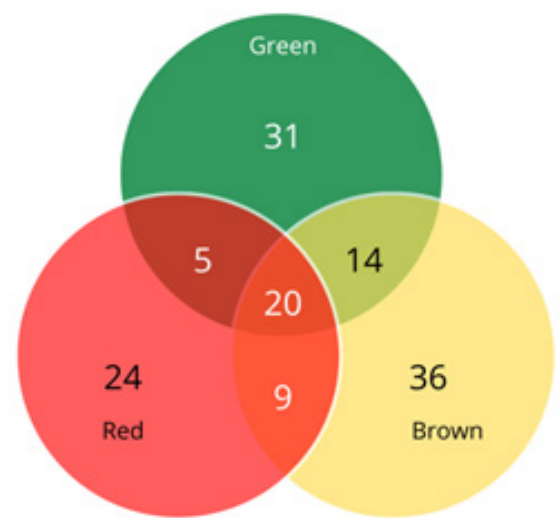

Gambar 1. Diagram hubungan spesies plankton dengan kolam air hijau, cokelat, dan merah.

Hubungan spesies plankton dari ketiga warna air kolam ditampilkan dalam Gambar 1. Ketiga warna air kolam memiliki kesamaan plankton sebanyak 20 spesies. Plankton yang hanya terdapat pada masing-masing kolam air hijau, cokelat, dan merah berturut-turut adalah 31, 36, dan 24 spesies. Kesamaan plankton yang terdapat pada kolam air hijau dan cokelat adalah sebanyak 14 spesies. Plankton yang terdapat pada kolam air cokelat dan merah adalah sebanyak 9 spesies. Sedangkan plankton yang terdapat pada kolam air hijau dan merah adalah 5 spesies.

Plankton spesifik pada warna hijau yang paling besar adalah M. aeruginosa, Radiococcus planktonicus, dan Entomoneis sp. Plankton spesifik pada warna cokelat yang paling besar adalah Chrysocapsa planktonica, Chroococcus sp., dan Amphora hendeyi sp. Plankton spesifik pada warna merah yang paling besar adalah 
Haematococcus pluvialis, Pseudoprorodon ellipiticus, dan Vorticella campanula. Terdapat spesies spesifik di masing-masing kolam yang berbeda warna air dipengaruhi oleh berbagai faktor lingkungan, salah satunya adalah faktor fisikokimia perairan (Gusmewati \& Deswati, 2018).

Komposisi jenis plankton

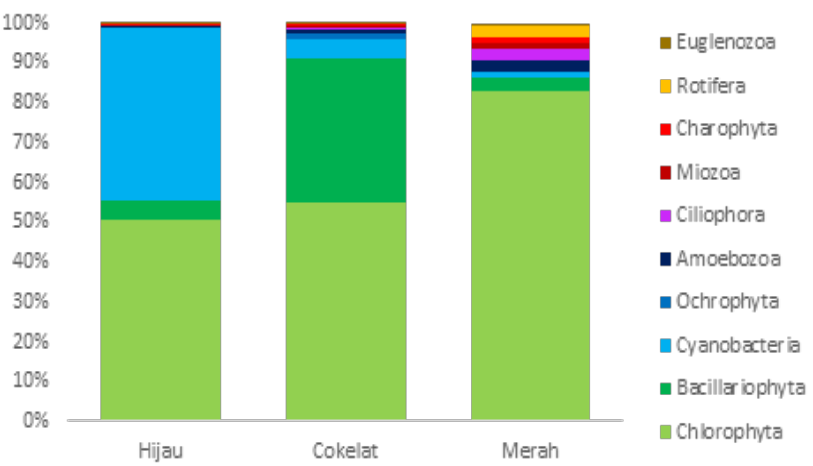

Gambar 2. Distribusi tingkat filum plankton yang mendominan pada kolam air hijau, cokelat, dan merah.

Komposisi plankton yang ditemukan di kolam budidaya ikan lele pada seluruh warna air kolam terdapat 15 filum yang terdiri dari 32 kelas. Berdasarkan hasil analisis komposisi jenis plankton pada tingkat filum (Gambar 2) didapatkan bahwa Chlorophyta mendominansi komposisi plankton di ketiga warna air. Persentase proporsi plankton Chlorophyta pada warna air kolam hijau, cokelat, dan merah berturut-turut adalah 50,46; 54,89; dan $82,78 \%$. Plankton lain yang mendominansi pada kolam air hijau adalah Cyanobacteria dengan persentase 43,53 \%; sedangkan kolam air cokelat adalah plankton Bacillariophyta dengan persentase $36,44 \%$.

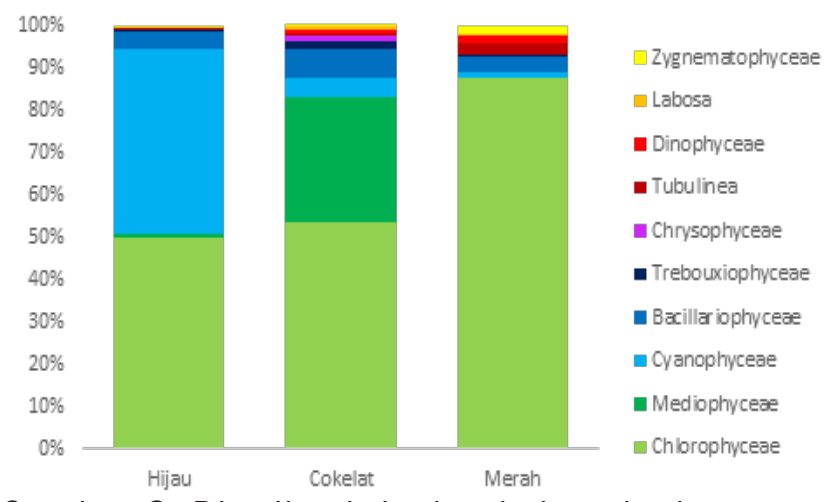

Gambar 3. Distribusi tingkat kelas plankton yang mendominan pada kolam air hijau, cokelat, dan merah.

Komposisi jenis tingkat kelas plankton pada warna air kolam hijau, cokelat, dan merah didominansi oleh Chlorophyceae. Persentase spesies Chlorophyceae masingmasing pada warna air kolam hijau, cokelat, dan merah adalah 49,87; 53,33; dan 87,51 \% (Gambar 3). Plankton pada kolam warna air hijau dominansi terbesar selain Chlorophyceae adalah plankton Cyanophyceae dengan persentase $41,76 \%$. Warna air cokelat juga didominansi oleh plankton Mediophyceae dengan persentase sebesar 29,62 \%. Chlorophyceae memiliki komposisi yang tinggi di ketiga warna air kolam, hal ini dapat disebabkan adanya nutrisi yang tinggi pada badan air, seperti kandungan nitrat $\left(\mathrm{NO}_{3}^{-}\right)$yang tinggi (Hoang et al. 2018; Lodang \& Kurnia, 2019).

\section{Dominansi plankton}

Tabel 2. Indeks dominansi (C) plankton pada kolam air hijau, cokelat, dan merah.

\begin{tabular}{cccc}
\hline \multirow{2}{*}{ Kolam } & \multicolumn{3}{c}{ Indeks dominansi (C) } \\
\cline { 2 - 4 } & SamplingI & Sampling II & Sampling III \\
\hline H1 & 0,39 & 0,28 & 0,16 \\
H2 & 0,73 & 0,32 & 0,38 \\
H3 & 0,22 & 0,29 & 0,19 \\
C1 & 0,19 & 0,23 & 0,28 \\
C2 & 0,25 & 0,25 & 0,31 \\
C3 & 0,24 & 0,26 & 0,45 \\
M1 & 0,43 & 0,75 & 0,18 \\
M2 & 0,75 & 0,48 & 0,52 \\
M3 & 0,62 & 0,75 & 0,28 \\
\hline
\end{tabular}

Analisis dominansi komunitas plankton yang didapatkan berkisar antara 0,16-0,75 (Tabel 2). Nilai dominansi dengan rentang tersebut tergolong dalam dominansi rendah yang berarti tidak ada spesies yang mendominansi di air kolam. Nilai indeks dominansi plankton terendah terdapat pada kolam Hijau 1 sampling ke III. Nilai indeks dominansi tertinggi terdapat pada kolam Merah 1 dan Merah 3 sampling ke II, serta Merah 2 sampling ke I. Nilai rata-rata indeks dominansi plankton antar warna adalah 0,33 pada kolam hijau, dan 0,27 pada kolam cokelat, sedangkan pada kolam merah adalah 0,53. Indeks dominansi tertinggi terdapat pada kolam air warna merah, sedangkan terendah terdapat pada kolam air warna cokelat. Indeks dominansi berkisar antara 0 sampai 1. Semakin kecil nilai indeks dominansi menunjukan bahwa tidak ada spesies yang mendominansi, sebaliknya semakin besar dominansi maka menunjukkan ada spesies tertentu yang mendominansi (Odum, 1996). Nilai indeks hasil analisis menunjukkan bahwa pada ketiga warna air kolam termasuk dalam kategori dominansi rendah. Hasil analisis sejalan dengan penelitian Sukma et al. (2016), yaitu nilai indeks dominansi plankton yang didapatkan pada kolam budidaya ikan lele media bioflok adalah 0,1-0,17. Penelitian Anetekhai et al. (2018) menunjukkan indeks dominansi plankton pada kolam benih ikan lele adalah 0,1858-0,2422. Berdasarkan uji Kruskal-Walis dari ketiga warna kolam dengan indeks dominansi (C) menunjukkan bahwa terdapat perbedaan signifikan antar warna kolam. Berdasarkan uji lanjut Mann-Whitney menunjukkan bahwa beda nyata terdapat pada kolam air merah terhadap hijau dan cokelat.

\section{Diversitas plankton}

Berdasarkan analisis komunitas plankton didapatkan hasil keanekaragaman (Shannon) plankton dengan nilai H' berkisar antara 0,57-2,12 (Tabel 3). Keanekaragaman plankton tertinggi terdapat pada kolam Hijau 1 pada sampling ke III, sedangkan nilai terendah adalah pada kolam Merah 3 pada sampling ke II. Nilai rata-rata keanekaragaman plankton antar warna antara lain kolam 
hijau dengan nilai rata-rata 1,61 dan 1,74 pada kolam cokelat, sedangkan pada kolam merah adalah 1,13. Hasil analisis keanekaragaman pada ketiga warna air kolam termasuk dalam kategori keanekaragaman sedang. Menurut Odum (1996), nilai indeks keanekaragaman (H') lebih besar sama dengan satu dan kurang dari sama dengan tiga $\left(1 \geq H^{\prime} \geq 3\right)$ termasuk dalam kategori keanekaragaman sedang dengan tekanan ekosistem rendah hingga sedang serta memiliki pertumbuhan cukup baik. Hasil analisis sejalan dengan penelitian yang dilakukan oleh Sukma et al. (2016), yaitu nilai indeks keanekaragaman plankton pada kolam budidaya ikan lele di media bioflok antara 2,87-3,43. Penelitian Anetekhai et al. (2018) menunjukkan indeks keanekaragaman plankton pada kolam benih ikan lele adalah 2,7672,824. Berdasarkan uji Kruskal-Walis dari ketiga warna kolam dengan indeks keanekaragaman $\left(H^{\prime}\right)$ menunjukkan bahwa terdapat perbedaan signifikan antar warna kolam. Berdasarkan uji lanjut Mann-Whitney menunjukkan bahwa beda nyata terdapat pada kolam air merah terhadap hijau dan cokelat.

Tabel 3. Indeks keanekaragaman ( $H^{\prime}$ ) plankton pada kolam air hijau, cokelat, dan merah.

\begin{tabular}{cccc}
\hline \multirow{2}{*}{ Kolam } & \multicolumn{3}{c}{ Indeks keanekaragaman $\left(\mathrm{H}^{\prime}\right)$} \\
\cline { 2 - 4 } & SamplingI & Sampling II & Sampling III \\
\hline H1 & 1,30 & 1,49 & 2,12 \\
H2 & 0,75 & 1,66 & 1,40 \\
H3 & 1,92 & 1,78 & 2,05 \\
C1 & 1,92 & 1,96 & 1,71 \\
C2 & 1,81 & 1,76 & 1,70 \\
C3 & 1,78 & 1,77 & 1,25 \\
M1 & 1,39 & 0,68 & 2,04 \\
M2 & 0,73 & 0,95 & 1,06 \\
M3 & 1,02 & 0,57 & 1,77 \\
\hline
\end{tabular}

0

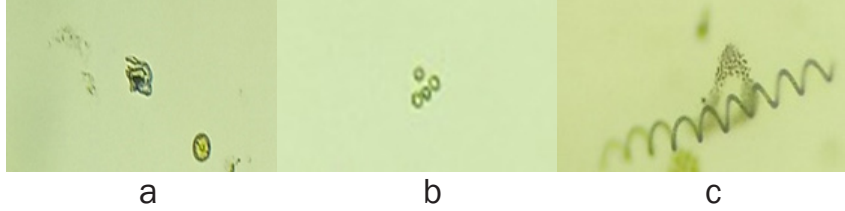

Gambar 4. Foto plankton yang mendominansi pada kolam air hijau, cokelat, dan merah. (a) Cyclotella sp.; (b) C. varigatus; (c) M. aeruginosa.

Spesies plankton pada warna air kolam hijau, cokelat, dan merah didominansi oleh spesies $C$. varigatus. $C$. varigatus memiliki distribusi yang luas berdasarkan dari hasil yang diperoleh. Plankton Chlorella mampu beradaptasi dengan lingkungan ekstrim, seperti dengan kadar amonia dan fosfat yang tinggi (Widiyani \& Dewi, 2014; de Lourdes et al., 2017). Dinamika dari C. varigatus pada ketiga warna air kolam memiliki hasil yang berbeda pada ulangan waktu (Gambar 3). Kolam warna air hijau pada sampling I memiliki jumlah C. arigatus sebesar 282,750 idv/l, selanjutnya meningkat pada sampling II menjadi 352,750 idv/l, dan menurun pada sampling III menjadi 254,000 idv/l. Kolam air cokelat memiliki jumlah $C$. varigatus pada sampling I sebesar 463,000 idv/l, meningkat pada sampling II dengan jumlah 1,977,500 idv/l, dan meningkat pada sampling III menjadi 3,745,000 idv/l. Kolam air merah memiliki jumlah C. varigatus pada sampling I sebesar 2,600,000 idv/l, turun pada sampling II dengan jumlah 791,250 idv/l, dan turun secara drastis pada sampling III menjadi 21,000 idv/l. Adanya penurunan jumlah dari C. varigatus dapat disebabkan adanya pengaruh kualitas air, seperti suhu, pH, nitrat, fosfat dan salinitas (Aprilliyanti et al. 2016).

Chlorella adalah fitoplankton cosmopolitan yang sering dijumpai di perairan tawar, hal ini dikarenakan Chlorella mampu beradaptasi dengan berbagai jenis kondisi perairan (Wigajatri et al., 2003; Widiyani \& Dewi, 2014). Sel Chlorella memiliki bentuk membulat atau bulat telur, dan merupakan alga bersel tunggal (uniseluler) namun terkadang ditemukan dalam bergerombol/ berkoloni (Apriliyanti et al., 2016). Chlorella selain itu juga merupakan agen bioremediasi yang baik, hal ini dikarenkan Chlorella memiliki tingkat toleransi yang tinggi terhadap kualitas air perairan dan hidup pada lingkungan yang tercemar serta dapat mengakumulasi logam berat dalam perairan (Apriliyanti et al., 2016; Kusuma \& Zulaika, 2014). Keberadaan C. vulgaris pada kolam dapat meningkatkan oksigen terlarut serta produktivitas primer perairan (Han et al., 2003).

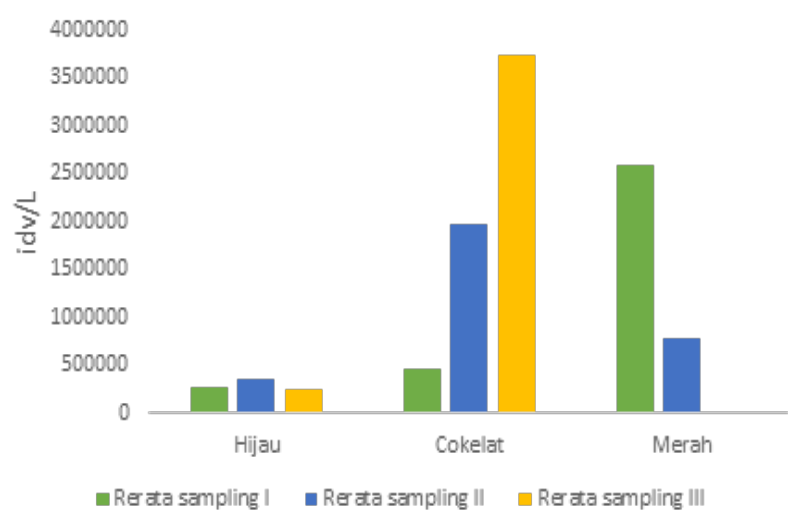

Gambar 5. Dinamika C. varigatus di kolam warna air hijau, cokelat, merah pada ulangan waktu. Satuan yang digunakan adalah individu per liter (idv/l).

Plankton pada kolam warna air hijau memiliki dominansi terbesar terdapat pada plankton $M$. aeruginosa dengan persentase $52,86 \%$. M. aeruginosa adalah cyanobacterium yang umum ditemukan pada perairan tinggi nutrisi atau perairan eutrofik (Tanabe et al., 2018). Dinamika dari $M$. aeruginosa pada kolam warna air hijau memiliki hasil yang berbeda pada ulangan waktu (Gambar 5). Dinamika plankton $M$. aeruginosa pada antar kolam warna air hijau cenderung menurun dari sampling I hingga sampling III. Kolam H1 pada sampling I memiliki jumlah $M$. aeruginosa sebesar $862,500 \mathrm{idv/l}$, selanjutnya meningkat pada sampling II menjadi 876,750 idv/l, dan menurun pada sampling III menjadi 123,750 idv/l. Kolam H2 pada sampling I memiliki jumlah M. aeruginosa sebesar 1,194,750 idv/l, selanjutnya menurun pada sampling II menjadi 553,500 idv/I, dan menurun pada sampling III menjadi 502,500 idv/I. Kolam H3 pada sampling I memiliki jumlah M. aeruginosa sebesar 180,000 idv/l, selanjutnya menurun 
pada sampling II menjadi 47,250 idv/l, dan turun pada sampling III menjadi 14,250 idv/I.

M. aeruginosa adalah cyanobacterium uniseluler pembentuk bloom yang paling umum di kolam. $M$. aeruginosa terdiri dari sel-sel kecil (diameternya hanya beberapa mikron) yang tidak memiliki selaput individual. Sel biasanya tersusun menjadi koloni (koloni besar yang dapat dilihat dengan mata telanjang) yang dimulai dalam bentuk bulat, namun kemudian kehilangan koherensi menjadi berlubang atau berbentuk tidak teratur (Zhong et al., 2019). M. aeruginosa telah dikenal luas sebagai spesies yang memiliki dampak serius dalam ekologi perairan, karena dapat menghasilkan racun yaitu microcystin serta menyebabkan harmful algal bloom. Microcystis dapat mempengaruhi produksi perikanan melalui dampak racun secara langsung dan pada jaring makanan di berbagai tingkat trofik. (Oberholster, 2004; Kumar \& Sinha, 2014; Lehman et al., 2010) Terjadinya blooming $M$. aeruginosa dapat disebabkan oleh berbagai macam kondisi lingkungan dan $M$. aeruginosa dapat berkembang pada perairan yang memiliki konsentrasi nutrisi tinggi, serta perubahan suhu musiman. Konsentrasi nitrogen dan fosfor, serta cahaya telah menjadi faktor penentu perkembangan Microcystis (Almanza et al., 2016).

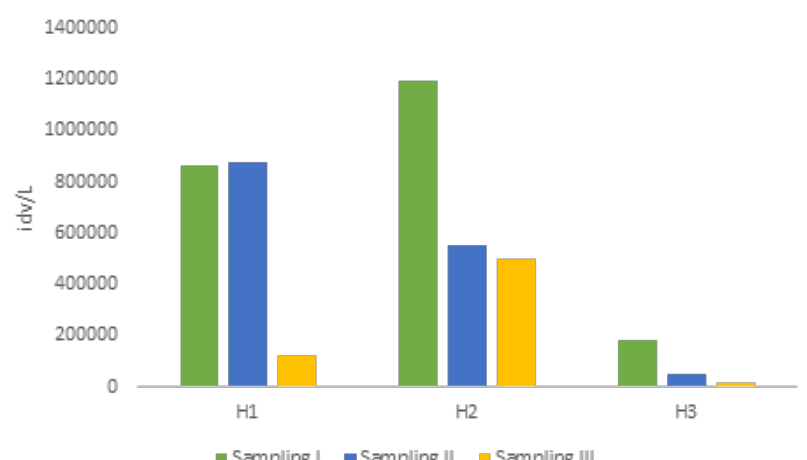

Gambar 6. Dinamika M. aeruginosa di kolam warna air hijau dengan ulangan waktu. Satuan yang digunakan adalah individu per Liter (idv/l).

Plankton pada kolam warna air cokelat memiliki dominansi terbesar kedua pada plankton Cyclotella sp. dengan persentase 33,33\%. Dinamika dari Cyclotella sp. pada kolam warna air cokelat memiliki hasil yang berbeda pada ulangan waktu (Gambar 5). Dinamika plankton Cyclotella sp. pada antar kolam warna air cokelat cenderung meningkat. Kolam C1 pada sampling I memiliki jumlah Cyclotella sp. sebesar 159,667 idv/l, selanjutnya meningkat pada sampling II menjadi 2,587,500 idv/l, dan menurun pada sampling III menjadi 1,035,000 idv/l. Kolam C2 pada sampling I memiliki jumlah Cyclotella sp. 2,392,500 idv/l, selanjutnya menurun pada sampling II menjadi 1,042,500 idv/I, dan meningkat kembali pada sampling III menjadi $1,717,500 \mathrm{idv} / \mathrm{I}$. Kolam C3 pada sampling I memiliki jumlah Cyclotella sp. 780,000 idv/l, selanjutnya meningkat pada sampling II menjadi 1,365,000 idv/l, dan pada sampling III menjadi 1,935,000 idv/l.

Cylotella sp. merupakan jenis diatom yang berbentuk cakram kecil dengan bagian tengah berbentuk rata dan terdapat pita lebar di bagian tepi. Sel Cyclotella berbentuk segi empat dan setiap sel mengandung banyak kloroplas berbentuk discoid (Vuuren, 2006). Cyclotella sp. memiliki nilai nutrisi yang baik untuk banyak spesies budidaya (Boyd, 2014). Spesies ini merupakan salah satu jenis plankton yang dapat menunjukan tingkat kualitas air perairan. Keberadaan dari Cyclotella sp. dapat menunjukan adanya polusi bahan organik menengah hingga tinggi, serta kandungan nutrisi yang tinggi. Perkembangan Cyclotella mengindikasikan adanya eutrofikasi karena pengaruh aktivitas manusia. Hal ini dikarenakan Cyclotella merupakan organisme yang toleran terhadap bahan organik (Szczepocka \& Szulc, 2009; Yang et al., 2020; Yussuf, 2020).

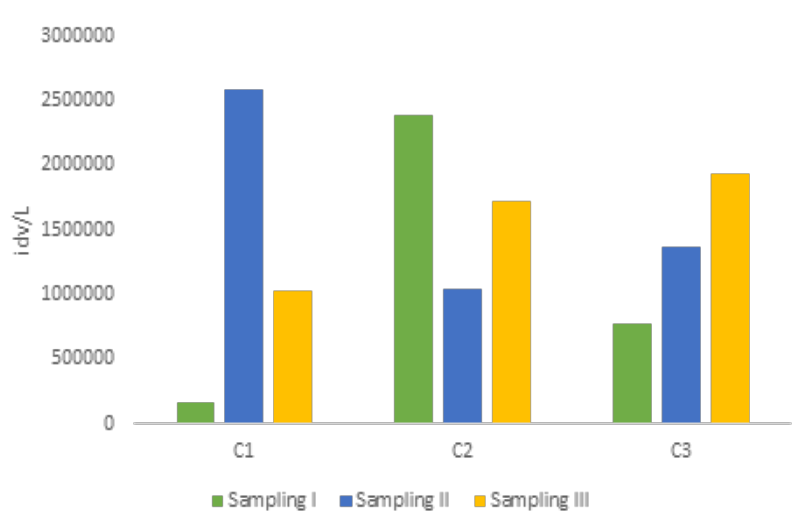

Gambar 7. Dinamika Cyclotella sp. di kolam warna air cokelat dengan ulangan waktu. Satuan yang digunakan adalah individu per Liter (idv/I).

Plankton pada kolam warna air merah memiliki dominansi plankton Haematococcus pluvialis dengan persentase 1,9\%. Dinamika dari $H$. pluvialis pada kolam warna air merah memiliki hasil yang berbeda pada ulangan waktu (Gambar 6). Dinamika plankton H. pluvialis pada antar kolam warna air merah cenderung menurun. Kolam M1 pada sampling I memiliki jumlah $H$. pluvialis sebesar 67,500 idv/l, selanjutnya menurun pada sampling II menjadi 60,000 idv/I, dan menurun pada sampling III menjadi 9,750 idv/l. Kolam M2 pada sampling I memiliki jumlah $H$. pluvialis $82,500 \mathrm{idv} / \mathrm{I}$, selanjutnya menurun pada sampling II menjadi 21,000 idv/I, dan meningkat kembali pada sampling III menjadi 6,750 idv/l. Kolam M3 hanya ditemukan pada sampling III dengan jumlah $H$. pluvialis sebesar $750 \mathrm{idv} / \mathrm{l}$.

Terdapat perbedaan dinamika antar sampling pada tiap spesies dominan di masing-masing kolam yang berbeda warna air. Perbedaan tersebut dapat dipengaruhi oleh berbagai faktor, seperti kualitas air, predasi maupun kematian alami plankton serta dekomposisi. Karakteristik lingkungan perairan yang secara fisiologis berpengaruh terhadap dinamika populasi plankton antara lain faktor fisikokimia perairan seperti intensitas cahaya, kecerahan, salinitas, oksigen terlarut, stratifikasi suhu, dan ketersediaan unsur hara nitrit dan fosfor, serta aspek biologis seperti aktivitas predasi oleh hewan, kematian alami, dan dekomposisi (Gusmewati \& Deswati, 2018; Hesti et al., 2018).

\section{Kualitas air}

Kualitas air pada ketiga kolam ditampilkan pada Tabel 4. Kolam dengan air berwarna hijau memiliki kadar oksigen terlarut rata-rata sebesar 0,95 mg/l, sedangkan air berwarna cokelat memiliki kadar oksigen terlarut ratarata sebesar 2,05 mg/I dan pada air berwarna merah 
memiliki kadar oksigen terlarut rata-rata sebesar 0,29 $\mathrm{mg} / \mathrm{l}$. Nilai rata-rata suhu air antar kolam pada kolam air hijau memiliki sebesar $28,64^{\circ} \mathrm{C}$, sedangkan pada kolam air berwarna cokelat sebesar $28,39^{\circ} \mathrm{C}$ dan pada air berwarna merah memiliki nilai rata-rata suhu air antar kolamnya adalah $27,57^{\circ} \mathrm{C}$. Kolam air berwarna hijau memiliki nilai rata-rata $\mathrm{pH}$ antar kolam sebesar 5,98; sedangkan pada kolam air berwarna cokelat memiliki nilai rata-rata $\mathrm{pH}$ antar kolam sebesar 6,78 dan pada kolam air berwarna merah sebesar 6,93. Kadar bahan organik pada kolam dengan air berwarna hijau memiliki nilai rata-rata sebesar $100,80 \mathrm{mg} / \mathrm{I}$ antar kolamnya, adapun pada kolam dengan air berwarna cokelat memiliki bahan organik rata-rata sebesar 197,23 mg/l dan pada kolam air merah sebesar $313,57 \mathrm{mg} / \mathrm{l}$. kolam merah dan coklat. Uji LSD pada parameter amonia menunjukan amonia pada air kolam warna coklat berbeda nyata dengan air kolam hijau dan air kolam merah, adapun kolam hijau dengan kolam merah tidak berbeda nyata. Uji lanjut pada parameter DO menggunakan uji T menunjukan nilai oksigen terlarut pada air kolam warna hijau memiliki beda nyata dengan air kolam warna merah dan coklelat, adapun nilai oksigen terlarut pada air kolam warna merah dan cokelat tidak ada beda nyata. Uji Mann-Whitney pada parameter bahan organik menunjukan adanya beda nyata antar kolam. Uji lanjut menggunakan uji Mann-Whitney pada parameter nitrit menunjukan warna air merah memiliki perbedaan nyata terhadap warna hijau dan coklat.

Berdasarkan hasil uji statistik tersebut, maka hanya

Tabel 4. Kualitas air kolam warna air hijau, cokelat, dan merah pada pengulangan kolam.

\begin{tabular}{lccccc}
\hline \multirow{2}{*}{ Kolam } & \multirow{2}{*}{ Sampling } & \multicolumn{5}{c}{ Kualitas air } \\
\cline { 2 - 6 } & & $\mathrm{DO}(\mathrm{mg} / \mathrm{l})$ & Suhu $\left({ }^{\circ} \mathrm{C}\right)$ & $\mathrm{pH}$ & Bahan organik $(\mathrm{mg} / \mathrm{l})$ \\
\hline \multirow{3}{*}{ Hijau } & I & $0,84 \pm 0,64^{\mathrm{a}}$ & $25,32 \pm 1,09$ & $6,01 \pm 0,02^{\mathrm{a}}$ & $98,90 \pm 31,45^{\mathrm{a}}$ \\
& II & $1,40 \pm 1,10^{\mathrm{a}}$ & $30,34 \pm 0,54$ & $6,05 \pm 0,17^{\mathrm{a}}$ & $141,70 \pm 63,66^{\mathrm{a}}$ \\
& III & $0,61 \pm 0,72^{\mathrm{a}}$ & $30,26 \pm 0,98$ & $5,87 \pm 0,11^{\mathrm{a}}$ & $61,79 \pm 15,31^{\mathrm{a}}$ \\
\multirow{3}{*}{ Cokelat } & I & $3,87 \pm 1,57^{\mathrm{b}}$ & $27,50 \pm 0,19$ & $6,70 \pm 0,02^{\mathrm{b}}$ & $180,5 \pm 15,92^{\mathrm{b}}$ \\
& II & $1,55 \pm 0,85^{\mathrm{b}}$ & $30,60 \pm 0,31$ & $7,06 \pm 0,12^{\mathrm{b}}$ & $169,12 \pm 11,34^{\mathrm{b}}$ \\
& III & $0,73 \pm 1,27^{\mathrm{b}}$ & $27,08 \pm 1,01$ & $6,57 \pm 0,06^{\mathrm{b}}$ & $242,07 \pm 12,16^{\mathrm{b}}$ \\
\multirow{3}{*}{ Merah } & I & $0,26 \pm 0,07^{\mathrm{b}}$ & $27,68 \pm 0,48$ & $7,13 \pm 0,10^{\mathrm{b}}$ & $355,94 \pm 22,82^{\mathrm{c}}$ \\
& II & $0,27 \pm 0,12^{\mathrm{b}}$ & $27,57 \pm 0,55$ & $6,83 \pm 0,12^{\mathrm{b}}$ & $352,57 \pm 9,58^{\mathrm{c}}$ \\
& III & $0,35 \pm 0,15^{\mathrm{b}}$ & $27,46 \pm 0,63$ & $6,82 \pm 0,17^{\mathrm{b}}$ & $252,20 \pm 63,63^{\mathrm{c}}$ \\
\hline
\end{tabular}

*Huruf berbeda menunjukan ada beda nyata.

Tabel 5. Amonia, nitrat dan nitrit pada air kolam hijau, cokelat dan merah.

\begin{tabular}{lccc}
\hline \multirow{3}{*}{ Kolam } & \multicolumn{3}{c}{ Kualitas air } \\
\cline { 2 - 4 } & $\begin{array}{c}\text { Amonia } \\
(\mathrm{mg} / \mathrm{l})\end{array}$ & $\begin{array}{c}\text { Nitrat }\left(\mathrm{NO}_{3}\right) \\
(\mathrm{mg} / \mathrm{l})\end{array}$ & $\begin{array}{c}\text { Nitrit }\left(\mathrm{NO}_{2}\right) \\
(\mathrm{mg} / \mathrm{l})\end{array}$ \\
\hline Hijau & $0,28 \pm 0,24^{\mathrm{a}}$ & $0,18 \pm 0,10$ & $0,09 \pm 0,10^{\mathrm{a}}$ \\
Cokelat & $3,09 \pm 0,86^{\mathrm{b}}$ & $1,88 \pm 2,51$ & $0,01 \pm 0,00^{\mathrm{a}}$ \\
Merah & $0,27 \pm 0,19^{\mathrm{a}}$ & $11,7 \pm 11,2$ & $0,48 \pm 0,01^{\mathrm{b}}$ \\
\hline
\end{tabular}

* Huruf berbeda menunjukan ada beda nyata;

Kadar amoniak dalam kolam air hijau, cokelat, dan merah memiliki nilai rata-rata antar kolam sebesar 0,28; 3,09; $0,27 \mathrm{mg} / \mathrm{l}$. Kadar nitrat $\left(\mathrm{NO}_{3}\right)$ dalam kolam air hijau, cokelat, dan merah memiliki nilai rata-rata antar kolam sebesar 0,18; 1,88; 11,7 mg/l. Kadar nitrit $\left(\mathrm{NO}_{2}\right)$ dalam kolam air hijau, cokelat, dan merah memiliki nilai rata-rata antar kolam sebesar 0,09; 0,01; 0,48 mg/l.

Berdasarkan uji ANOVA ( $\mathrm{pH}$, amonia, dan nitrat) dan uji Kruskal Wallis (DO, suhu, bahan organik dan nitrit). Ketiga warna air kolam terhadap ketujuh parameter kualitas air yang diukur, terdapat perbedaan signifikan pada parameter $\mathrm{DO}, \mathrm{pH}$, bahan organik, amonia dan nitrit. Berdasarkan uji lanjut ANOVA menggunakan uji LSD (Least Significant Differences) pada $\mathrm{pH}$ menunjukkan bahwa pada kolam air hijau memiki perbedaan yang signifikan dengan
5 parameter (DO, pH bahan organik, nitrit, dan amonia) yang memiki perbedaan nyata antar kolam. Hubungan antara kualitas air kolam dengan nilai $\mathrm{H}^{\prime}, \mathrm{C}$, dan $\mathrm{N}$ plankton hanya dilakukan terhadap 5 parameter tersebut dengan menggunakan uji korelasi dari nilai indeks diversitas dan indeks dominansi masing-masing kolam dengan parameter DO, pH bahan organik, nitrit, dan amonia. Adapun hasil uji regresi dan korelasi ditampilkan pada Tabel 6.

Tabel 6 menunjukan koefisien korelasi antara parameter kualitas air dengan nilai indeks diversitas ( $\left.\mathrm{H}^{\prime}\right)$, indeks dominansi $(\mathrm{C})$, serta kepadatan $(\mathrm{N})$ plankton. Berdasarkan klasifikasi rentang koefisien korelasi menurut Walpole (1994), nilai koefisien korelasi pada rentang 0 - 0,2 termasuk dalam kategori sangat lemah/tidak ada hubungan, 0,2-0,4 tergolong lemah, sedangkan pada rentang koefisien 0,4-0,6 termasuk dalam kategori sedang/biasa. Hal tersebut menunjukkan parameter DO, bahan organik, nitrit, dan amonia memiliki nilai sedang terhadap nilai keanekaragaman plankton $\left(\mathrm{H}^{\prime}\right)$ dan dominansi plankton (C). Adapun pada parameter $\mathrm{pH}$ memiliki korelasi yang sangat lemah terhadap nilai H' dan C plankton. Nilai korelasi terhadap kepadatan plankton $(\mathrm{N})$ menunjukan hubungan yang sangat lemah dengan parameter bahan organik dan amonia, dan hubungan lemah dengan parameter $\mathrm{DO}, \mathrm{pH}$, nitrit. Nilai $\mathrm{R}^{2}$ dari uji regresi pada parameter DO dengan H' dan C plankton sebesar 0,17 serta terhadap $\mathrm{N}$ sebesar 0,03 menunjukkan hanya $17 \%$ 
Tabel 6. Hasil uji regresi dan korelasi parameter kualitas air dengan keanekaragaman $\left(\mathrm{H}^{\prime}\right)$,dominansi plankton (C), dan kepadatan plankton $(\mathrm{N})$.

\begin{tabular}{lcccccc}
\hline \multirow{2}{*}{$\begin{array}{l}\text { Parameter } \\
\text { korelasi }\end{array}$} & \multicolumn{2}{c}{ Keanekaragaman plankton $(\mathrm{H})$} & \multicolumn{2}{c}{ Dominansi plankton $(\mathrm{C})$} & \multicolumn{2}{c}{ Kepadatan plankton $(\mathrm{N})$} \\
\cline { 2 - 7 } & $\begin{array}{c}\text { Pearson } \\
\text { Correlation }\end{array}$ & $\mathrm{R}^{2}$ & $\begin{array}{c}\text { Pearson } \\
\text { Correlation }\end{array}$ & $\mathrm{R}^{2}$ & $\begin{array}{c}\text { Pearson } \\
\text { Correlation }\end{array}$ & $\mathrm{R}^{2}$ \\
\hline Oksigen terlarut & 0,41 & 0,17 & 0,41 & 0,17 & 0,27 & 0,03 \\
pH & 0,15 & 0,02 & 0,18 & 0,03 & 0,25 & 0,06 \\
Bahan organik & 0,62 & 0,38 & 0,62 & 0,38 & 0,08 & 0,01 \\
Nitrit & 0,64 & 0,41 & 0,64 & 0,41 & 0,31 & 0,10 \\
Amonia & 0,61 & 0,37 & 0,62 & 0,38 & 0,17 & 0,03 \\
\hline
\end{tabular}

pengaruh dari DO terhadap diversitas serta dominansi plankton serta 3\% terhadap kepadatan plankton. Nilai R2 dari uji regresi sebesar 0,02 dan 0,03 pada parameter $\mathrm{pH}$ dengan $\mathrm{H}^{\prime}$ dan $\mathrm{C}$ plankton serta 0,06 pada $\mathrm{N}$ menunjukan bahwa hanya $2 \%, 3 \%$ serta $6 \%$ pengaruh dari nilai $\mathrm{pH}$ terhadap nilai H', C, dan kepadatan plankton. Nilai R2 pada parameter bahan organik didapatkan sebesar 0,38 pada H' dan C plankton serta 0,01 pada N, yang menunjukan pengaruh bahan organik terhadap diversitas serta dominansi plankton sebesar 38\% dan 1\% terhadap kepadatan plankton. Nilai $\mathrm{R}^{2}$ pada parameter nitrit sebesar 0,41 pada H' dan $\mathrm{C}$ plankton serta 0,1 pada $\mathrm{N}$ menunjukan pengaruh nitrit pada diversitas dan dominansi plankton sebesar $41 \%$ dan pada kepadatan plankton sebesar $10 \%$. Nilai $\mathrm{R}^{2}$ pada parameter amonia sebesar 0,37 pada $\mathrm{H}^{\prime}$ dan 0,38 pada $\mathrm{C}$ plankton serta 0,03 pada $\mathrm{N}$ menunjukan pengaruh amonia terhadap nilai H' dan C plankton sebesar $37 \%$ dan $38 \%$ dan $3 \%$ pada kepadatan plankton.

Hasil korelasi antara parameter kualitas air dengan plankton tersebut menunjukan bahwa kualitas air memiliki pengaruh namun tidak kuat terhadap komunitas plankton. Penelitian Pratiwi et al. (2015) memiliki hasil yang berbeda dimana kualitas air memiliki korelasi yang kuat terhadap plankton $(0,8)$, dengan parameter DO memiliki pengaruh paling besar. Penelitian Novia et al. (2016) menunjukan kepadatan plankton dipengaruhi oleh DO $(0,67)$, namun berkorelasi sangat lemah dengan pH $(-0,05)$. Makmur et al. (2011) menunjukan bahwa nilai korelasi antara kualitas air dengan kelimpahan plankton tidak memiliki hubungan yang signifikan $(<0,05)$. Penelitian Sharma et al. (2016) menunjukan kepadatan plankton berhubungan kuat dengan $\mathrm{pH}(-0,9)$, DO $(0,9)$, dan nitrit $(-0,8)$. Pirzan \& Pong-Masak (2008) menunjukan bahwa bahan organik memiliki korelasi sebesar 0,61 terhadap diversitas fitoplankton, hal ini sama dengan hasil penelitian ini dimana bahan organik berpengaruh secara sedang terhadap diversitas maupun dominansi plankton. Adanya perbedaan hasil korelasi antara parameter kualitas air dengan plankton pada penelitian ini dengan referensi lain dapat disebabkan karena perbedaan jenis dominan plankton yang ada dan jenis perairan/lokasi penelitian.

\section{KESIMPULAN}

Struktur komunitas plankton pada air kolam yang berbeda warna menunjukkan terdapat 15 filum yang terdiri dari 32 kelas. Plankton yang dominan pada kolam warna air hijau adalah $M$. aeruginosa, sementara pada kolam cokelat dan merah adalah C. varigatus. Nilai diversitas dan dominansi pada ketiga warna air cenderung stabil moderat, karena termasuk dalam kategori sedang.

\section{DAFTAR PUSTAKA}

Almanza, V., O. Parral, C.E.de.M. Bicudo, C. Baezal, J. Beltran, R. Figueroal \& R. Urrutia. 2016. Occurrence of toxic blooms of Microcystis aeruginosa in a central Chilean ( $36^{\circ}$ Lat. S) urban lake. Revista Chilena de Historia Natural. 89: 8.

Anetekhai, M.A., E.O. Clarke, O.A. Osodein \& M.T. Dairo. 2018. Physical, chemical parameters and plankton in a tropical earthen pond catfish farm in Badagry, Nigeria. Int. J. Fish. Aquac. 10 (6): 71-76.

Aprilliyanti, S., T.R. Soeprobowati \& B. Yulianto. 2016. Hubungan kemelimpahan Chlorella sp. dengan kualitas lingkungan perairan pada skala semi masal di BBBPBAP Jepara. Jurnal Ilmu Lingkungan 14 (2): 77-81.

Barus, T. A. 2004. Pengantar Limnologi Studi Tentang Ekosistem Air Daratan. Medan: USU Press.

Boyd, C.E. 1982. Water Quality Management for Pond Fish Culture. Elsevier, Amsterdam.

Boyd, C.E. 2014. Silicon diatoms in aquaculture. Global Aquaculture Advocate 17: 38-39.

de Lourdes, F.M.M., R.R.M.D. Josefina, M.M.C. Ulises \& M.R.A. de Jesus. 2017. Tolerance and nutrients consumption of Chlorella vulgaris growing in mineral medium and real wastewater under laboratory conditions. Open Agriculture. 2 (1): 394-400.

Gao, H., S. Zhang, R. Zhao \& L. Zhu. 2018. Plankton community structure analysis and water quality bioassessment in Jiulong Lake. IOP Conf. Ser.: Earth Environ. Sci. 199022031.

Han, S., Z. Zhang \& L. Yu. 2003. Using chlorella and effective microorganisms to optimize aquatic ecological structure and to regulate water quality. Ying Yong Sheng Tai Xue Bao 14 (1): 101-4. Chinese. PMID: 12722449.

Heddy, S. 1994. Pengantar Ekologi. Rajawali Press. Jakarta.

Hesti, P., A. Damar \& Sulistiono. 2018. Phytoplankton community structure in the Estuary of Donan River, Cilacap, Central Java, Indonesia. Biodiversitas. 19 
(6): 2104-2110.

Hoang, H.T.T, T.T. Duong, K.T. Nguyen, Q.T.P. Le, M.T.N. Luu, D.A. Trinh, A.H. Le, C.T. Ho, K.D. Dang, J. Nemery, D. Orange, \& J. Klien. 2018. Impact of anthropogenic activities on water quality and plankton communities in the Day River (Red River Delta, Vietnam). Environ Monit Assess. 190: 67.

Junaidi, M., Nurliah \& F. Azhar. 2018. Community structure of phytoplankton and its relationshp to waters quality in Lombok Strait, North Lombok District, West Nusa Tenggara, Indonesia. International Journal of Oceans and Oceanography. 12 (2): 159-172.

Kumar, B \& A. Sinha. 2014. Microcystis Toxic Blooms In Fish Culture Ponds And Their Biological And Chemical Control. International Journal of scientific \& technology research 3(3): 398.

Kusuma, R.W.A \& E. Zulaika. 2014. Potensi Chlorella sp. sebagai bioakumulator logam berat Kadmium. Jurnal Sains dan Seni Pomits. 3 (2).

Lehman, P.W., S.J. Teh, G.L. Boyer, M.L.Nobriga, E. Bass \& C. Hogle. 2010. Initial impacts of Microcystis aeruginosa blooms on the aquatic food web in the San Francisco Estuary. Hydrobiologia 637: 229-248.

Lodang, H \& N. Kurnia. 2019. Distribution and abundance of plankton in The Downstream of Jeneberang Rive. J Phys. Conf. Ser. 1244: 012011.

Makmur, Rachmansyah \& M. Fahrur. 2011. Hubungan keragaman fitoplankton dengan kualitas air di Pulau Bauluang, kabupaten Takalar, Sulawesi Selatan. Prosiding Forum Inovasi Teknologi Akuakultur. 961968.

Mc.Garaghan, A. 2018. Tiny Drifters: a guide to the phytoplankton along The California Coast. Kudela Biological and Satellite Oceanography Laboratory, University of California.

Moersidik, S \& Hardjojo. 1998. Water Analysis and Quality. Karunika. Jakarta.

Nontji, A. 2008. Plankton Laut. LIPI Press. Jakarta.

Novia, R., Adnan \& I.R. Ritonga. 2016. Hubungan parameter fisika-kimia perairan dengan kelimpahan plankton di Samudera Hindia bagian Barat Daya. Depik 5 (2): 6776.

Oberholster, P.J. 2004. Microcystis aeruginosa: souce of toxic microcystins in drinking water. African Journal of Biotechnology. 3: 159-168.

Odum, E.P. 1996. Environmental Accounting: Energy and environmental decision makin. John Wiley and Sons, Inc. New York.

Pirzan, A.M \& P.R. Pong-Masak. 2008. Hubungan Keragaman Fitoplankton dengan Kualitas Air di Pulau Bauluang, kabupaten Takalar, Sulawesi Selatan. Biodiversitas. 9 (3): 217-221.

Pratiwi, E.D., C.J. Koenawan \& A. Zulfikar. 2015. Hubungan kelimpahan plankton terhadap kualitas air di Perairan Malang Rapat Kabupaten Bintan Provinsi Kepulauan Riau. Jurnal Umrah. 28: 1-14.

Rahmatullah., M.S. Ali, \& S. Karina. 2016. Keanekaragaman dan dominansi plankton di estuari Kuala Rigaih
Kecamatan Setia Bakti Kabupaten Aceh Jaya. Jurnal IImiah Mahasiswa Kelautan dan Perikanan Unsyiah. 1 (3): 325-330.

Sari, D.P., S. Kamal, \& N. Hanim. 2018. Komposisi jenis plankton di Danau Lut Tawar Kabupaten Aceh Tengah. Prosiding Seminar Nasional Biotik. 108-114.

Sari, D.R., J.W. Hidayat \& R. Hariyati. 2018. Struktur komunitas plankton di kawasan wana wisata Curug Semirang Kecamatan Ungaran Barat, Semarang. Jurnal Akademika Biologi. 7 (4): 32-37.

Sharma, R.C., N. Singh \& A. Chauhan. 2016. The influence of physico-chemical parameters on phytoplankton distribution in a head water stream of Garhwal Himalayas: A case study. Egyptian Journal of Aquatic Research. 42: 11-21.

Shirota, A. 1966. The Plankton of South Vietnam: Freshwater and Marine Plankton. Over Tech Coop Agent. Japan.

Sukma, RA., N.A. Pamukas \& I. Putra. 2016. The abundance of plankton in fish breeding basin African Catfish (Clarias gariepinus) with the frequency of inoculant bactreria in engineering biofloc. Jurnal Online Mahasiswa Universitas Riau. 3 (1):1-15.

Sunarto, A. Pangastuti, Suranto, E. Mahajoeno \&E. Setioningsih. 2014. The T-RFLP analysis of methanogenic Community uring The na aerobic fermentation of Tju likuid waste. Global Journal Science Frontier Research. 16 (4): 15-21.

Szczepocka, E \& B. Szulc. 2009. The use of benthic diatoms in estimating water quality of variously polluted River. Oceanological and Hydrobiological Studies. 38 (1): 17-26.

Tanabe, Y., Y. Hodoki, T. Sano, K. Tada \& M.M. Watanabe. 2018. Adaptation of the Freshwater Bloom-Forming Cyanobacterium Microcystis aeruginosa to Brackish Water Is Driven by Recent Horizontal Transfer of Sucrose Genes. Frontiers in microbiology. 9: 1150.

Thirunavukkarasu, K., P. Soundarapandian, D. Varadharajan \& B. Gunalan. 2013. Phytoplankton Composition and Community Structure of Kottakudi and Nari Backwaters, South East of Tamil Nadu. J Aquac Res Development. 5: 211.

Vuuren, S.J.V., T.Jonathan, V.G.Carin \& G. Annelise. 2006. Easy Identification Of The Most Common Freshwater Algae. South African: North-West University NoorowesUniversitiet.

Walpole, R.E. 1995. Pengantar Statistika, Ed. 3. Gramedia Pustaka. Jakarta.

Widiyani, P. \& E.R.S. Dewi. 2014. Penurunan konsentrasi logam berat kadmium (Cd) dan pertumbuhan mikroalga Chlorella vulgaris pada media kultur. Bioma: Jurnal Ilmiah Biologi. 3 (2): 17-26.

Wigajatri R.P, A. Handojo, H. Kurniawan \& N.B. Prihantini. 2003. Studi karakteristik fluoresensi Chlorella sp.: Pengaruh $\mathrm{pH}$ terhadap pengkulturan. Makara Journal of Technology. 7 (2): 83-88.

Yang, J., J. Yong, Y. Ruyu, L. Xingche, Z. Jie, W. Naichen \& K. Wang. 2020. Applicability of Benthic Diatom Indices Combined with Water Quality Valuation for Dish Lake from Nanjishan Nature Reserve, Lake Poyang. Water. 12 (10): 2732. 
Yussuf, Z.H. 2020. Phytoplankton as bioindicators of water quality in Nasarawa reservoir. Katsina State Nigeria Acta Limnologica Brasiliensia. 32 (4).

Zhong, C., Y. Guijun, Q. Boqiang, Wilhelm, W. Steven, L. Yu, H. Lihua, R. Zheng, Y. Hongwei \& Z. Zhou. 2019. Effects of mixing intensity on colony size and growth of Microcystis aeruginosa. Annales de Limnologie International Journal of Limnology. 55: 12. 